\title{
EPISTEMIC COMMUNITIES AND SERVICE DELIVERY CHOICES IN SPANISH MUNICIPAL ADMINISTRATIONS
}

\author{
Miquel SALVADOR, Clara RIBA \\ Universitat Pompeu Fabra, Barcelona, Spain
}

\begin{abstract}
This article contributes to the debate on the use of alternative formulas for public service provision with arguments related to epistemic communities' influence. Drawing on the literature on models of local public service delivery, the role of internal epistemic communities is discussed and tested through the consideration of two different communities related to specific municipal areas such as personal and urban services. The results demonstrate that the association of urban services' epistemic communities with alternative formulas for direct provision to deliver services is greater than in the case of personal services' epistemic community. Those findings contribute to the academic debate not only with arguments and evidence that reinforces the role of variables included in previous research but also by introducing the role of epistemic communities in determining some policy options (as the use of local public-service delivery formulas).
\end{abstract}

Key Words: epistemic community, local government, service delivery, outsourcing.

\section{Introduction}

There is a growing body of literature regarding the determinants of the production and delivery of local public services (Brown and Potoski 2003a, Joassart-Marcelli and Musso 2005, Lamothe et al. 2008). Despite their increasing number, the studies undertaken in this field display little consensus on which factors most strongly influence the choice of mechanisms by local governments for public service provision. The current debate concerns the options available to local governments, i.e. whether to opt for the direct provision of certain public services or to choose between alternative mechanisms, such as the creation of specialpurpose bodies dependent on the local administration, or contracting services out to external agents, as in the 'make or buy dilemma' (Leiblein et al. 2002, Lamothe et al. 2008).

In the context of this literature, our study aims to add to it further by introducing the role of epistemic communities, an approach that fits neatly in the 'make or buy' debate. However, in addition to the variables already tested (those variables that we use as controls) we also concentrate on those variables that can illustrate the presence of epistemic communities and their role in public-service delivery choices.

The increasing amount of literature on the role played by epistemic communities in the framing of public policies has defined these communities as networks of recognized experts in a specific knowledge field; their tasks are directed towards contributing to the collective debate on subjects related to their field of knowledge, recommending policies and identifying key points for possible negotiation (see, among other authors, Haas 1992, Radaelli 1995, Jordana and Levi-Faur 2004). "It is the prestige, training and reputation of its members that generate the sort of expertise valued by political elites" (Haas 1992: 17) and which serve to reduce the uncertainty present in the elaboration, implementation and reform of public policies, which are rapidly becoming more complex (Marier 2008). Communities of specialists play a decisive role in promoting or rejecting innovations and reforms in the field of public policy, since they have 
the explicit objective of influencing the decisions taken by public authorities (Toke 1999 , Radaelli 2000). Moreover, they can also use their expert knowledge to create uncertainty to increase the strategic advantage of their purposes (Morin 2014).

Even if there is no clear consensus on how to identify an epistemic community, there is some evidence that highlights the existence of such articulated groups in local governments around different sectoral areas (related to the policy field of intervention). This paper refers to the incidence of two sectoral communities on the selection of particular service-provision mechanisms controlling for other specific variables highlighted by the literature.

In addition to epistemic communities, there are other variables that affect the choice of publicservice delivery formulas. Both theoretical and empirical evidence (Ferris and Graddy 1986, Bel and Fageda 2007, Levin and Tadelis 2010, González-Gómez et al. 2011) indicate that the characteristics of the service are a central factor in choosing a mechanism for provision. In other words, certain services are better catered for being delivered by a particular management formula. Such suitability has tended to be associated, according to arguments from the field of economics and more specifically from transaction costs theory, with the specificity of the service and with the difficulty in measuring it (Brown and Potoski 2003a). Our study recognizes the explanatory weight of the nature of the service but it assumes it is constant between the distinct town councils that provide them.

Other studies, in evaluating the decision regarding the management formulas for public service provision, award explanatory power to variables such as the capacities and management structure of the local government or its position in the market of suppliers (Lamothe et al. 2008). The evaluation covers among other areas, the structure of the market, the management model and the capacity to incorporate citizens and business into the process (Navarro Yañez et al. 2008), the metropolitan location of the municipality or its industrial structure, the professionalization of its management level, its fiscal capacity, and the perceptions of the agents involved including public employees (Brown and Potoski 2003a, Joassart-Marcelli and Musso 2005, Fernandez et al. 2008, Zullo 2009). Such research considers not only the specific characteristics of the service but also those of the municipal organisation taking the management formula decision. Although its arguments are based on results from environments removed from the reality of Spanish public administration, they provide the starting point for the present analysis.

The discussion of the role of epistemic communities and its characterization in the literature is complemented by introducing empirical evidence coming from the analysis of public-service delivery mechanisms in every town council in Catalonia with over 5000 inhabitants. The approximation proposed is based on town councils, which, independently of the nature of the service in question, opt between direct service supply by units of the council itself or by looking for other alternatives. If they pursue the latter they can opt for provision via the creation of special purpose bodies depending on the council (the argument being that they offer greater flexibility, specialisation and ease of cooperation with the representatives of the sector) or outsourcing, thus incorporating private agents into public service delivery.

This article starts with a conceptual discussion on the modes of local service provision and the role of different epistemic communities that forms the basis of our hypothesis. Subsequently, this is followed by a section on the data and methods proposed to test the hypothesis together with a presentation of our results and consequent discussion. The article finishes by stressing the role of epistemic communities on local service delivery and with some concluding remarks. 


\section{Modes of Service Provision and Epistemic Communities}

This study focuses on the role of certain internal professional collectives which, from technical (not political) positions, reflect opposing tendencies in public management, as they are explanatory variables of the alternative service provision mechanisms selection.

Following the argument of the 'flight' of core structures from public administrations, three modes of public service provision are identified, according to their proximity to the central structure of the administration: (1) direct supply by units of the council itself, (2) provision via the creation of special purpose bodies depending on the council, and (3) delivery by outsourcing. For our research purposes, we contrast direct provision by the council itself (1) to alternative formulas (2 and 3 ) that are argued to offer greater flexibility, specialisation and ease of cooperation with the representatives of the sector with which the council relates for public service delivery.

The alternatives available for the supply of specific public services, like many internal public administration decisions in Spain, have a considerable technical content, and thus are usually left off in the agenda of the maximum political authority (Salvador Serna 2005). Ideally, epistemic communities that dominate theory and/or experience in the relevant field not only make sense of, and outline alternatives to new or uncertain situations, but also fill gaps in information and formulate a set of technically or scientifically based reasons and arguments to support a particular course of policy action. As Marier (2008: 5) argues, "when a policy problem is highly technical, experts tend to dominate the policy process making it difficult for other political actors to play a potent role", which therefore extends the epistemic community's room for manoeuvre.

In their role in either the promotion or rejection of innovations and reforms in public management, epistemic communities appear to be no different from other interest groups, such as trade unions or business associations. Nevertheless, epistemic communities share at least two fundamental features that distinguish them from the classic interest groups. First, epistemic communities do not directly represent any group in particular that might be affected by the decision in question. It is evident that from their contribution to debates will benefit some actors and it will harm others, but this is not the fundamental motive for their intervention; they do not act as lobbies to explicitly represent a particular sector, but instead they justify their actions as promoting the best interests of the society as a whole. This assumption, however, is relativized by authors such as Houlihan (1999), who underlines the wisdom of at least questioning the affirmation that it is possible to possess significant knowledge regarding the definition of the course of a policy and at the same time, to display no personal or collective vested interest in the subject. Second, the only power of negotiation that epistemic communities possess is their capacity to generate a current of solid opinion, sustained by the intellectual prestige and experience of their members. In contrast to interest groups, they possess no tools to promote a specific approach or decision other than those derived from their authority as specialists.

Individuals with similar profiles establish informal networks for information and knowledge exchange to produce common positions with regard to specific management options. Epistemic communities share specific understandings, values, and beliefs, even though their members might come from a variety of disciplinary backgrounds or professional settings and their members may have the power of validating knowledge in the domain of their expertise (Tamtik and Sá 2012). Even if there is no clear body of knowledge, the concept of 'epistemic arbitrage' introduces the role of professionals that mediate between knowledge pools for strategic advantage and, if successful, how they can become the 'arbiters' on what knowledge and practices are most influential in their area (Seabrooke 2014). The related concept of 'communities of practice' reinforces the weight of shared notions of competent performance that are fundamentally epistemic and recognized among peers. These communities can be 
defined in terms of "intersubjective social structures that constitute the normative and epistemic ground for action, but they also are agents, made up of real people, who - working via network channels, across national borders, across organizational divides, and in the halls of government - affect political, economic, and social events" (Adler and Pouliot 2011: 18-19). Their influence is especially relevant when policy-makers face complex and problematic situations in which neither causes nor solutions are clear-cut and actors' interests remain ambiguous - in other words, a scenario where 'ideas' matter most (Weishaupt 2010). We argue that, in the field of public-service provision modes, these ideas come from different 'epistemic communities' of top managers and high-ranking technical staff, who are located in decisionmaking positions, and are members of networks of experts in policy making that develop within and around municipal organizations.

Our study identifies two sectoral professional communities as being important in service formula decisions. The first sectoral epistemic community is defined around urban services. This is a widespread community composed of external professional associations (especially related to engineering and town planning), specialized urban consultants and public officials in local administrations working in urban services (such as town planning and management services such as water supply or street cleaning). In regards to public service provision, a common feature of this community is its proximity to management in the private sector along with their traditional opposition to the direct public management of services. Unfortunately there is a lack of available data about the local public officials and about the unities of the regional administration that promote a public-private relationship, although there are professional associations that could be related to this community - such as engineers (Col/legi d'Enginyers) - important consultants and service-provider firms - such as the building companies specialized in public works - and some Departments of the regional government - such as the Department of Territorial Policy and Public Works - that have a clear orientation to the public-private relationship promotion. The authors' own qualitative data - coming from interviews and direct observation in medium sized municipalities (Tarragona and Sant Cugat del Vallès), supralocal governments (Diputació de Barcelona and Diputació de Girona) and municipal associations (Associació Catalana de Municipis) - support the argument of professional linkages among top managers and high-ranking technical positions related to urban services areas. In order to identify the impact of the urban services epistemic community, our paper assumes the presence of an epistemic community of urban services in the management of the most common local urban services - despite differences in specificity and measurability - as the top managers and high-ranking technical positions in these services have similar profiles.

The second sectoral epistemic community is defined around social services (also called 'personal services' in local Spanish administration, due the kind of areas covered by this level of government). This field includes a wide range of different professionals from services as wide ranging as culture, social services, nursery schools, care of senior citizens, immigration or libraries. Due to this diversity, they are a less consolidated epistemic community, even though there are agents related to it. These agents stem from NGOs (non-governmental organisations) and other similar third-sector associations, such as academic research centres - specifically related to political and social sciences - and regional administration departments with clear orientations to social care assistance (Departament de Benestar i Familia). Again there are no statistics about the profiles of the local public officials in charge of these areas. The authors' own qualitative fieldwork, based on interviews and direct observation in big and medium sized municipalities (Barcelona and Tarragona), supralocal organisations ('Patronat Flor de Maig', now integrated in the Diputació de Barcelona), and professional networks promoted by regional administration (through the Departament de Benestar i Familia) supports the existence of a community consisting of top managers and of those in high-ranking technical positions related to personal services areas. Even with its heterogeneous composition, the top managers and high-ranking technical staff in charge of personal services could be characterised as a community regarding the direct service provision. This is because of their low identification with 
the classic public administration and their reticence for private sector collaboration. Furthermore, they are known for having unwillingness to engage with the private companies to provide services, except perhaps in the case of agreements with non-profit organisations.

The characteristics of the two sectoral communities just described lead to the formulation of the following hypothesis:

The epistemic community related to personal services will be more prone to direct service provision than the epistemic community of urban services (that will tend to promote service provision through other formulas such as special purpose bodies or outsourcing).

We have incorporated a set of control variables into our model that the literature found to be related with the adoption of the different forms of public service delivery. The expected effect on direct service provision of such variables is based on previous research. We expect a negative effect in the case of the existence of markets around the city that will be able to provide public services (measured through municipality location in a metropolitan area) (Brown and Potoski 2003a), a negative effect of fiscal stress (financial situation of the local government) (Zullo 2009) and no effect from the political orientation of the municipal government (Joassart-Marcelli and Musso 2005). We included three more variables whose effect on the direct service provision needs to be explained in more detail. These are the private-type of local public employment, the asset specificity and the service measurability.

Spain follows the Continental European or 'Rechtsstaat' tradition of public administration (Pollitt and Bouckaert 2004), namely 'closed' civil service systems, with specific regulations covering entry via competitive examinations, lifelong contracts, systems of remuneration and standardized career paths, which is associated with a certain rigidity in human resources management. However, for certain posts, councils may choose to contract staff under private sector employment conditions, a formula associated with a greater flexibility in personnel management (Salvador and Ramió 2009). If one of the main reasons to outsource several local public services is to overcome public administration rigidities, town councils with a greater proportion of private-type local public employment do not need to opt for public service formulas that are different from direct provision. The private-type of local public employment can be understood as an indicator of flexibility to manage human resources in continental models of public administration. For this reason, we expect a positive effect of this variable on direct service provision.

The other two variables are "asset specificity" and "service measurability". They measure the characteristics of the services. Asset specificity is the degree of specialized investments required to produce the service - such as specific location, specialized human skills, specialized tools or temporary requirements. Service measurability is a measure of the difficulty that the local government has in measuring the outcomes of the service and/or in monitoring the activities required for delivering the service. Regarding the characteristics of the service provided, Brown and Potoski's (2003a) results show that the mode of service delivery is affected by the asset specificity and service measurability. Brown and Potoski (2003a) in their study on service production decisions collected data on asset specificity and service measurability for a list of the United States local services from city managers and majors through a survey conducted by the authors. Their results show that as the asset specificity increases from medium to high, the probability of direct service provision decreases and when the difficulty of measuring increases from medium to high, the probability of direct internal production increases. In consequence, we expect a negative effect on direct service provision for services with high asset specificity and a positive effect for services with high difficulty of service measurability. 


\section{Data}

When reviewing the proposed explanations of the role of political and institutional factors in the selection of mechanisms for local public service provision, research shows significant variations in the weight of the variables considered, due to the sample employed. This article aims to contribute to this debate by providing evidence based on data collected in 2007 and 2011 by the Fundación Carles Pi $i$ Sunyer de Estudios Autonómicos y Locales of all municipalities of over 5000 inhabitants in the Autonomous Community of Catalonia, from a total of 187 town councils. The city of Barcelona has been excluded from the analysis as an outlier, due both to its higher level of self-government compared with other towns and cities and to its population size: 1668700 of the 7210508 inhabitants of all Catalonia in 2007 (Statistical Institute of Catalonia). For each local administration the data file combines data on its structure and functioning at political and management level, its special purpose bodies and related organisations, its public services and the management formula employed in their production, and financial and budgetary information.

The exhaustiveness of the information compiled is combined with the fact that the data file covers all the local administrations in Catalonia. Consequently, this data source permits the inclusion in this analysis of the distinct management options implemented by councils with significant internal variation, in population size, socio-economic features and government and institutional characteristics, among others. The data supplied here are not an opinion but evidence, gathered through the city council officials and further tested by consulting complementary information sources, to confirm their validity.

The 23 services included in the study are: public lighting, cemeteries, refuse collection, street cleaning, drinking water supply, sewerage, maintenance of public parks, access to population centres, selective refuse collection, environmental protection, public libraries, popular and traditional culture, social services, public sports facilities, music conservatories and schools, kindergartens, adult education, food and beverage control, markets, civil protection, slaughterhouses, crime prevention and public actions related to health. These are statutory services established by the Law 7/1985, 2 April, Regulating the Bases of Local Government and other services which in practice are usually provided at this administrative level in Spain. In total, 4 301 units of analysis are available, for which the mode of service provision by each municipality is documented in 3509 cases. The size and characteristics of the towns included in the study permit the consideration of the pattern of municipal service provision as constant together with the assumption that the set of municipalities share a similar pattern of public services, both statutory and additional.

The variables employed are now described. The dependent variable is the direct service provision in 2011. It is a dummy variable with $1=$ "direct provision by the council itself" and $0=$ "otherwise". The zero-category includes outsourcing - legal formulas of concessions, shared profit contracts, leasing, agreements and commercial enterprises/joint cooperatives - and delivery via special purpose bodies - with formulas of autonomous body, commercial enterprise, or public commercial entity. The explanatory variables are also dummy variables that indicate the existence of the two epistemic communities: the Epistemic community of urban services formed by the professional collective managing urban services $(1=$ "epistemic community of urban services", $0=$ "otherwise") and the Epistemic community of personal services formed by the professional collective managing personal services $(1=$ "epistemic community of personal services", $0=$ "otherwise"). In the two explanatory variables, the value of 1 is given when there are members of the corresponding epistemic communities in the provision of the service. There is a group of services (food and beverage control, markets, civil protection, slaughterhouses, crime prevention and public actions related to health) in which neither the epistemic communities of urban services nor of personal services can be found. 
These services (that constitute $26 \%$ of the cases) are too diverse for identifying any other epistemic community in them.

In addition to the dependent and explanatory variables, we introduced the variable direct service provision in 2007 and a set of control variables that, according to the literature, can have an effect on the probability of direct service provision. The first group of control variables refers to the characteristics of the municipality and its government. These are:

Metropolitan area. It is a dummy variable ( $1=$ "Municipality located in a metropolitan area", $0=$ "otherwise").

The Political orientation of the local government. It is calculated as the mean of the position on the left-right scale of each party forming part of the government coalition, weighted by the percentage of councillors that each supplies to it. The formula employed is:

$$
\text { Ideological orientation of municipal government }=\sum_{i=1}^{k} \frac{C i}{E}-W i
$$

with $k=$ number of parties that form the government; $C_{i}=$ number of councillors of party $i ; W_{i}=$ ideological position of party $i$ and $E=$ total number of councillors in the government. Data comes from the Barómetro de Opinión Política del Centro de Estudios de Opinión, July 2008.

Fiscal stress. It represents the difficulties that each municipality has in borrowing and it is the quotient between consolidated expenditure plus recognised liabilities (interest and amortisations included in Chapters 3 and 9 of the expenditure budget) and ordinary revenue (included in Chapters 1 to 5 of consolidated revenue) (Bel et al. 2010).

Private-type local public employment. It is the percentage of the council's total number of employees with contractual relationships equivalent to those in the private sector.

The second group of control variables refers to the characteristics of the service. Brown and Potoski (2003a) provide data of the asset specificity and service measurability for a list of services in a 1 to 5 scale. Higher values indicate that the service is more assets specific or more difficult to measure, respectively. The authors did an adaptation of it to the services provided by Catalan municipalities. The calculus of the asset specificity and service measurability values for the Catalan local services has been based on the values of Brown and Potoski study (2003a). Firstly, the list of services present in the Brown and Potoski's article (2003a) was confronted with the list of local services included in the Catalan study. We found some Catalan services with no equivalent and some others subdivided in two or three services in the Brown and Potoski's list (2003a). The decision taken was the following: for those Catalan local services that have a unique equivalent service in Brown and Potoski's study (2003a), the value of it has been taken; for the Catalan local services subdivided into two or three equivalent services in Brown and Potoski's table (2003a), the average of their values has been taken; for the rest of the services, those that don't have any equivalent service in Brown and Potoski's study (2003a), the values for asset specificity and service measurability have been decided by the authors who have based their decision on the analogy with other services that are similar as regards the specialized investments and the 'difficulty-to-measure' outcomes and to monitor the activities required to deliver the service. Table 3 in the Appendix shows the adaptation of Brown and Potoski's (2003a) values of asset specificity and service measurability to the services provided by the Catalan municipalities undertaken by the authors. Once we have obtained the values for these two characteristics of the services, we created two new variables called High asset specificity and High difficulty of service measurability. They take the value of 
asset specificity and service measurability respectively when this value is above the mean, and zero when it is equal or below the mean. The rationale for this operationalisation is that we assume that asset specificity and service measurability do not have any effect on the probability of direct service provision when they are low but they have an effect (negative and positive respectively) when they cross the threshold located at their mean.

Table 1 displays the list of variables included in the analysis, along with their expected effects on the dependent variable and the corresponding descriptives.

Table 1

Variables employed in the analysis and expected effect on service provision

\begin{tabular}{|l|l|r|r|r|r|r|}
\hline & $\begin{array}{c}\text { Expected } \\
\text { effect }\end{array}$ & \% & Min & Max & Mean & St. Dev. \\
\hline Dependent variable & & & & & & \\
\hline Direct service provision in 2011 & & 71.8 & & & & \\
\hline Explanatory variables & & & & & & \\
\hline Urban services epistemic community & Negative & 43.5 & & & & \\
\hline Personal services epistemic community & Positive & 30.4 & & & & \\
\hline Control variables & & & & & & \\
\hline Direct service provision in 2007 & Positive & 73.3 & & & & \\
\hline Metropolitan area & Negative & 19.6 & & & & \\
\hline Political orientation of the government & No effect & & 2.93 & 8.27 & 4.71 & 1.03 \\
\hline Fiscal stress & Negative & & 0.01 & 0.33 & 0.09 & 0.05 \\
\hline Private-type local public employment & Positive & & 3.92 & 93.55 & 56.17 & 19.35 \\
\hline High asset specificity & Negative & & 0.00 & 4.09 & 1.74 & 1.83 \\
\hline High difficulty of service measurability & Positive & & 0.00 & 3.76 & 1.58 & 1.67 \\
\hline
\end{tabular}

Source: Observatori de Govern Local de Catalunya 2007. Fundació Carles Pi i Sunyer; Brown and Potosky (2003a)

\section{Methods}

Because our dependent variable is dichotomous and not continuous, linear regression models are not appropriate in this study. Instead, the logistic regression model is one in which:

the dependent variable $y$ that takes only values 1 and $0-$ is transformed into one new variable called "logit" that is equal to the natural logarithm of the odds-ratio of the probability $\pi$ that $y$ takes value 1 .

$$
\text { logit }=\ln \left(\frac{\pi}{1-\pi}\right)
$$

With this transformation the dependent variable is continuous and it can be expressed as a linear combination of the explanatory variables. As a result, the logistic models are appropriate when the dependent variable is dichotomous. In addition to the problem of non-continuous dependent variable, our data presents a hierarchical structure in which our units of analysis the services provided - are grouped into municipalities. This hierarchical structure suggests the possibility of the existence of a correlation among the observations pertaining at the same municipality. And, when this occurs, the appropriate technique to use is the multilevel modelling. 
In consequence, to test the hypotheses proposed, a multi-level logistic causal model was estimated, in which the variable representing the public-service management formula in 2011 was predicted from the presence of epistemic communities in 2007 - once the effect of the management formula in 2007 and of a set of variables related to the institutional and contextual characteristics of the municipality and of the services in 2007 was controlled. Each service provided by the municipalities constitutes an observation (first-level of analysis) and the observations are grouped in municipalities (second-level of analysis). This strategy allows the testing of the effect of the presence of epistemic communities in a municipality in a specific moment in the management formula of the services some years later avoiding endogeneity problems.

Previously to the estimation of the multi-level logistic regression we tested if, as assumed, there is independence in the mode of service provision across municipalities. For this reason, we initially test if there is a 'municipality effect' with the estimation of a two-level null model. It is a model with only an intercept and municipality effects whose specification is the following:

$$
\ln \left(\frac{\pi_{i j}}{1-\pi_{i j}}\right)=\beta_{0}+u_{0 j}
$$

Here, ${ }^{\pi_{i j}}$ is the probability of direct provision of the service ${ }^{i}$ in a municipality $\tilde{f}$ in 2011 ; $\beta_{0}$ is the intercept; and is $u_{0 j}$ the random effect specific to the municipality $\tilde{f}$. The random effect is assumed to follow ${ }^{0 j}$ a normal distribution with the variance $\sigma_{u D}^{2}$. In the case where the variance of the random effect had been found significant, a multi-level model is needed because of the existence of intra-class correlation. Then, in a second step we will introduce our explanatory and control variables. The specification of the full model is the following:

$$
\ln \left(\frac{\pi_{i j}}{1-\pi_{i j}}\right)=\beta_{0}+\beta_{1}-X 1_{i j}+\beta_{2}-X 2_{i j}+\sum_{k} \gamma_{k}-Z k_{i j}+u_{0 j}
$$

Here, $X 1_{i j}$ and $X 2_{i j}$ are our two explanatory variables. They signal the presence of each one of the epistemic communities in the service $\tilde{i}$ delivered by the municipality $\tilde{f} ; Z K_{i j}$ are the control variables; $\beta_{1}, \beta_{2}$, and $\gamma_{k}$ are the coefficients of the explanatory and control variables respectively. When the variance of the random effect $u_{0 j}$ becomes non-significant we have to interpret that the explanatory and control variables explain all the differences between municipalities.

The models have been estimated with the STATA command xtmlogit, applying the Maximum Likelihood estimation using the adaptive quadrature with 7 integration points.

\section{Results and Discussion}

Table 2 presents the estimates of the two models of prediction for the probability of direct management versus other management forms. The first model estimated, M0, which does not include explanatory variables, confirms that multi-level techniques are advisable in this study. It can be observed that the residual variance among councils is significant and considerable. This indicates that, as hypothesized, there exists a 'municipality effect', in the sense that the services belonging to the same municipality have management forms more similar to each other than to the services belonging to other councils.

Having justified through MO the suitability of applying a multi-level model to the data, the second column of Table 2 presents the results of the estimation of the probability of direct 
management versus other management forms, taking as explanatory and control variables the set of variables described in Table 1.

Probability of direct service provision in 2011. Multi-level logistic regression

\begin{tabular}{|c|l|l|}
\hline \multicolumn{1}{|c|}{ M0 } & \multicolumn{1}{c|}{ M1 } \\
\hline Sectoral epistemic communities & & \\
\hline Urban services epistemic community & & $-2.035^{* * *}$ \\
\hline Personal services epistemic communities & & $-1.017^{* * *}$ \\
\hline Control variables & & \\
\hline Direct service provision in 2007 & & $4.723^{* * *}$ \\
\hline Metropolitan area & & $-0.533^{*}$ \\
\hline Left-Right position of the government & & 0.135 \\
\hline Fiscal stress & & $-3.035^{+}$ \\
\hline Private employment contracts & & 0.005 \\
\hline High specificity & & $-0.120^{* *}$ \\
\hline High difficult to measure & $0.970^{* * *}$ & -0.091 \\
\hline Constant & $0.129^{* * *}$ & 0.319 \\
\hline Residual variance among municipalities & $4,162.0$ & $1,257.8$ \\
\hline Deviance (= -2· Log likelihood) & 3,509 & 2,680 \\
\hline Number of observations & 187 & 151 \\
\hline Number of municipalities & & \\
\hline
\end{tabular}

+ Significant at a $\leq 0.10$; * Significant at $a \leq 0.05 ;{ }^{* *}$ significant at $a \leq 0.01 ;{ }^{* * *}$ significant at $\mathrm{a} \leq 0.001$

Source: Observatori de Govern Local de Catalunya 2007. Fundació Carles Pi i Sunyer; Brown and Potoski (2003a).

The results confirm the importance of the presence of sectoral epistemic communities on the mode of municipal service provision and they provide evidence in favour of our hypotheses. The epistemic communities of both urban services and personal services have a significant and negative effect on the probability of direct service management. In terms of Tamtik and Sá (2012), both communities have the power of validating knowledge in the domain of their expertise and, exercising 'epistemic arbitrage' (Seabrooke 2014), both become the 'arbiters' on what practices are most influential in their area. As Table 2 shows, this means that the probability of outsourcing or management through special purpose bodies is higher when one of these two epistemic communities is present than when they are not.

However, the fact that the probability of not having direct management is higher for the epistemic community of urban services than for the epistemic community of personal services provides evidence in favour of our hypothesis. That is, although the probability of direct management is higher when there is an absence of epistemic communities ruling the service, the epistemic community of urban services is less prone to direct management than the epistemic community of personal services. These results could be understood as the effect of how professional linkages among top public managers and high-ranking technical positions related to urban services areas with external professional associations and specialized urban consultants working in this field, favours their proximity to management in the private sector along with their opposition to the direct public management of services. In the case of personal services community, even their heterogeneity, the results could be understood in terms of their low identification with classic public administration and by their reticence for private sector collaboration (except perhaps in the case of agreements with non-profit organisations). 
As we argue in the previous section, the field of public-service provision modes constitute an scenario where 'ideas' matter most (Weishaupt 2010) and, consequently, some results can be explained in terms of the influence of both epistemic communities composed by top managers and high-ranking technical staff, who are located in decision-making positions in urban services and personal services areas, that are members of networks of experts in policy making that develop within and around municipal organizations.

Regarding the control variables, the impact of the mode of service provision in 2007 is significant and especially noticeably to inform the mode of service provision in 2011, as a reflex of inertia in a crisis environment in the local administrations. Additionally, as regards the effects of the characteristics of the services and the contextual effects of the municipality, the results displayed in Table 2 confirm partially our expectations. Those services with high asset specificity have higher probabilities of not being provided directly and this result is independent of the city location and its financial situation. In addition, the political orientation of the local government does not have any effect on the mode of service delivery as we expect. However, the variable related to the difficulty of service measurability is not significant although its coefficient has the expected positive sign. This lack of significance could be attributed to the presence of the variable mode of service provision in 2007 that captures its effect.

The results of control variables are in accordance with other bodies of research that have incorporated indicators of the urban context of cities (Brown and Potoski 2003a, Brown and Potoski 2003b, Fernandez et al. 2008, Bel and Fageda 2011). These results allow us to confirm that councils located in metropolitan areas tend to use outsourcing for public service (or, at least, other alternative formulas than direct provision). The political orientation of the municipal government, another factor underlined by various studies (Fernandez et al. 2008, JoassartMarcelli and Musso 2005), is not significant in our study, but the obtained results must be contextualized in the Spanish administrative system. As public management issues in Spain have traditionally been omitted from the agenda of public debate - being reserved for more 'technical' spheres, especially the sub-central levels of government and administration (Salvador Serna 2005) - the impact of the political ideology variable does not significantly affect the choice of management options for the local public service delivery. Also, in accordance with the literature, the results show that councils with financial difficulties will tend to use alternative formulas other than direct service provision, such as the creation of special purpose bodies or outsourcing. But the Spanish context contributes to the explanation of the impact of the 'local government fiscal stress' variable (Joassart-Marcelli and Musso 2005, Zullo 2009). The regulatory framework allows the creation of special purpose bodies (quasiautonomous entities ultimately dependent on the council) and it gives the councils considerable flexibility to borrow independently from their parent authority - a strategy commonly employed by fiscally stressed councils. There are other studies that discuss the effect of local public employment, conceived of as an interest group, on the type of public service delivery (Fernandez et al. 2008, Bradbury and Waechter 2009) and that focus on variables such as the percentage of public employees in relation to the population or the degree of unionisation of public employees (Bel and Fageda 2007). In order to contribute not only to this literature but also to introduce institutional context features regarding public employment, our analysis focuses on the characteristics of public employment in terms of the type of labour contract used as an indicator of the flexibility to manage human resources in continental models of public administration. The results on the field of public-employee management do not support the argument of the use of alternative formulas to direct provision as options to overcome public administration rigidities, as this variable is not significant. The results are also aligned, partially, with studies that emphasize the incidence of service characteristics on the mode of service provision. The effect of high asset specificity is negative over direct provision as it is expected in Brown and Potoski (2003a). But the effect of the high difficulty of service measurability is not significant, possibly because the main decisions related with this variable were taken in a previous period, during the first half of the 2000 and its impact is captured by the variable direct 
service provision in 2007.

\section{Conclusion}

The results of this study contribute to the academic debate on the use of alternative formulas for public service provision not only with arguments and evidence that reinforces the role of variables included in previous research but also by introducing the role of epistemic communities in determining some policy options (as the use of the local public-service delivery formulas).

The evidence confirming the direction of control variables connects the study in the afore-mentioned academic literature on local public service delivery. However, the results allow us to introduce new insights pertaining to the epistemic communities' role as it has been highlighted in the results and discussion section. The association of the epistemic community related to urban services with alternative formulas to direct provision to deliver services is confirmed, and it is greater than in the case of personal services' epistemic community.

Finally, all the data used in this study comes from a single region, Catalonia, and the exhaustive nature of the data and the period (prior to the present economic crisis) reinforces their value in contributing to the academic debate on local public-service provision formulas. The contribution on local service-delivery alternatives is also relevant to the debate about the rescaling and redistribution of competences among different levels of government, which is currently being promoted by Spain through the Ley 27/2013, de 27 de diciembre, de racionalización y sostenibilidad de la Administración Local (Law 27/2013, from 27 December for the rationalization and sustainability of local administration). The data and discussion offered in the article is also relevant in order to reshape the map of actors involved in this process. One promising research avenue is to look more closely at those epistemic communities that have been discussed in this article and their contribution to institutional change.

\section{Appendix}

In order to calculate the values of asset specificity and service measurability for the 23 local services provided by Catalan municipalities included in the study, we have elaborated a table of equivalence for each one of them with one or several services from the list included in the Brown and Potoski (2003a) study (Table 3). The values for services in the first column are equal to (or the average in the case of several equivalent services) the corresponding values of services listed in the second one. For services with any equivalent in Brown and Potoski's list (2003a), the estimates have been undertaken by the authors. 
Table 3

Asset specificity and service measurability for Catalan municipal public services

\begin{tabular}{|c|c|c|c|}
\hline $\begin{array}{l}\text { Services in Catalan } \\
\text { municipalities }\end{array}$ & $\begin{array}{l}\text { Equivalent services in } \\
\text { Brown \& Potoski (2003) }\end{array}$ & $\begin{array}{c}\text { Asset } \\
\text { specificity }\end{array}$ & $\begin{array}{c}\text { Service } \\
\text { measurability }\end{array}$ \\
\hline Public lighting & Electricity utility management & 4.08 & 2.96 \\
\hline Cemeteries & & 2.37 & 2.41 \\
\hline Refuse collection & $\begin{array}{l}\text { Commercial solid waste collection } \\
\text { Residential solid waste collection }\end{array}$ & 3.03 & 2.02 \\
\hline Street cleaning & Street / Parking lot cleaning & 2.26 & 2.00 \\
\hline Drinking water supply & $\begin{array}{l}\text { Water distribution } \\
\text { Water treatment }\end{array}$ & 4.03 & 2.40 \\
\hline Sewerage & Sewerage collection and treatment & 4.09 & 2.36 \\
\hline $\begin{array}{l}\text { Maintenance of public } \\
\text { parks }\end{array}$ & Parks and landscape maintenance & 2.33 & 2.11 \\
\hline $\begin{array}{l}\text { Access to population } \\
\text { centres }\end{array}$ & $\begin{array}{l}\text { Operation of para-transit systems } \\
\text { Traffic signal installation and } \\
\text { maintenance } \\
\text { Traffic control and parking } \\
\text { enforcement }\end{array}$ & 3.00 & 2.49 \\
\hline Selective refuse collection & $\begin{array}{l}\text { Solid waste disposal } \\
\text { Residential solid waste collection }\end{array}$ & 3.17 & 2.09 \\
\hline Environmental protection & & 3.00 & 3.5 \\
\hline Public libraries & Operation of libraries & 3.50 & 2.61 \\
\hline $\begin{array}{l}\text { Popular and traditional } \\
\text { culture }\end{array}$ & $\begin{array}{l}\text { Operation of cultural and arts } \\
\text { programs }\end{array}$ & 3.00 & 3.26 \\
\hline Social services & Personnel services & 2.58 & 3.31 \\
\hline Public sports facilities & & 3.50 & 2.80 \\
\hline $\begin{array}{l}\text { Music conservatories and } \\
\text { schools }\end{array}$ & $\begin{array}{l}\text { Operation of convention centres/ } \\
\text { auditoriums }\end{array}$ & 3.58 & 2.77 \\
\hline Kindergartens & $\begin{array}{l}\text { Child welfare programs } \\
\text { Operation of day-care facilities }\end{array}$ & 3.44 & 3.76 \\
\hline Adult education & & 3.00 & 3.26 \\
\hline $\begin{array}{l}\text { Food and beverage } \\
\text { control }\end{array}$ & Sanitary inspection & 3.06 & 2.57 \\
\hline Markets & & 2.50 & 2.00 \\
\hline Civil protection & & 3.80 & 3.25 \\
\hline Slaughterhouses & & 3.00 & 2.60 \\
\hline Crime prevention & Crime prevention/control & 3.37 & 3.60 \\
\hline $\begin{array}{l}\text { Public actions related to } \\
\text { health }\end{array}$ & Public health programs & 3.46 & 3.74 \\
\hline
\end{tabular}

Asset specificity and service measurability are measured in a 1 to 5 scale. Higher values indicate more asset specificity and that it is more difficult to measure the service, respectively.

Source: Own elaboration based on Brown and Potoski (2003a)

\section{References}

ADLER E., POULIOT V. (2011), International practices, International Theory 3 (1), 1-36.

BEL G., FAGEDA X. (2007), Why do local governments privatise public services? A survey of empirical studies, Local Government Studies 33 (4), 517-534.

BEL G., FAGEDA X. (2011), Big Guys Eat Big Cakes: Firm Size and Contracting in Urban and Rural Areas, International Public Management Journal 14 (1), 4-26. 
BEL G., FAGEDA X., MUR M. (2010), Why are services privatized in (small) municipalities? Empirical evidence on solid waste and water, Hacienda Pública Española 192 (1), 33-58.

BRADBURY M. D., WAECHTER G. D. (2009), Extreme outsourcing in local government: at the top and all but the top, Review of Public Personnel Administration 29 (3), 230-248.

BROWN T. L., POTOSKI M. (2003a), Transaction costs and institutional explanations for government service production decisions, Journal of Public Administration Research and Theory 13 (4), 441-468.

BROWN T. L., POTOSKI M. (2003b), Contract-management capacity in municipal and county governments, Public Administration Review 63 (2), 153-164.

FERNANDEZ S., RYU J. E., BRUDNEY J. L. (2008), Exploring variations in contracting for services among American local governments: do politics still matter? The American Review of Public Administration 38 (4), 439-462.

FERRIS J., GRADDY E. (1986), Contracting out: For what? With whom? Public Administration Review 46 (4), 332-344.

GONZÁLEZ-GÓMEZ F., PICAZO-TADEO A. J., GUARDIOLA J. (2011), Why do local governments privatize the provision of water services? Empirical evidence from Spain, Public Administration 89 (2), 471-492.

HAAS P. M. (1992), Introduction: Epistemic Communities and International Policy Coordination, International Organization 46 (1), 1-35.

HOULIHAN B. (1999), Anti-Doping Policy in Sport: The Politics of International Policy Coordination, Public Administration 77 (2), 311-334.

JOASSART-MARCELLI P., MUSSO J. (2005), Municipal service provision choices within a metropolitan area, Urban Affairs Review 40 (4), 492-519.

JORDANA J., LEVI-FAUR D. (2004), The Politics of Regulation in the Age of Governance, in: JORDANA J., LEVI-FAUR D. (eds.), The Politics of Regulation: Institutions and regulatory reforms for the age of governance, Edward Elgar Publishing, Cheltenham, pp. 1-28.

LAMOTHE S., LAMOTHE M., FEIOCK R. C. (2008), Examining local government service delivery arrangements over time, Urban Affairs Review 44 (1), 27-56.

LEIBLEIN M. J., REUER J. J., DALSACE F. (2002), Do make or buy decisions matter? The influence of organizational governance on technological performance, Strategic Management Journal 23 (9), 817-833.

LEVIN J., TADELIS S. (2010), Contracting for government services: Theory and evidence from U.S. cities, The Journal of Industrial Economics 58 (3), 507-541.

MARIER P. (2008), Empowering Epistemic Communities: Specialised Politicians, Policy Experts and Policy Reform, West European Politics 31 (3), 513-533.

MORIN J.-F. (2014), Paradigm shift in the global IP regime: The agency of academics, Review of International Political Economy 21 (2), 275-309.

NAVARRO YAÑEZ C. J., MAGNIER A., RAMÍREZ M. A. (2008), Local governance as government-business cooperation in western democracies: analysing local and intergovernmental effects by multi-level comparison, International Journal of Urban and Regional Research 32 (3), 531-547.

POLLITT C., BOUCKAERT G. (2004), Public management reform: a comparative analysis, Oxford University Press, Oxford.

RADAELLI C. M. (1995), The Role of Knowledge in the Policy Process, Journal of European Public Policy 2 (2), 159-183.

RADAELLI C. M. (2000), Policy transfer in the European Union: institutional isomorphism as a source of legitimacy, Governance 13 (1), 25-43.

SALVADOR SERNA M. (2005), La función pública autonómica como institución: ¿Buscando alternativas o reforzando un modelo? Los casos de la Comunidad de Madrid y la Generalitat de Catalunya, Revista Española de Ciencia Política 12, 129-151.

SALVADOR M., RAMIÓ C. (2009), Nuevas fórmulas de prestación de servicios públicos 
locales: experiencias y propuestas sobre los determinantes de la externalización en Cataluña, in: RAMIÓ C. (ed.), La colaboración público-privada y la creación de valor público, Diputació de Barcelona, Barcelona, pp. 81-104.

SEABROOKE L. (2014), Epistemic arbitrage: Transnational professional knowledge in action, Journal of Professions and Organization 1 (1), 49-64.

TAMTIK M., SÁ C. M. (2012), The Role of Experts in the European Union's Research Policy, Review of Policy Research 29 (4), 449-466. 97-102.

TOKE D. (1999), Epistemic Communities and Environmental Groups, Politics 19 (2),

WEISHAUPT J. T. (2010), A silent revolution? New management ideas and the reinvention of European public employment services, Socio-Economic Review 8 (3), 461-486.

ZULLO R. (2009), Does fiscal stress induce privatization? Correlates of private and intermunicipal contracting, 1992-2002, Governance 22 (3), 459-481.

Initial submission: 22.07.2015

Revised submission: 26.10 .2015

Final acceptance: 04.12.2015

Correspondence: Department of Political and Social Sciences, Universitat Pompeu Fabra, C. Ramon Trias fargas 25-27, 08005, Barcelona, Spain

E-mail: clara.riba@upf.edu 
